\title{
Institutional Innovation: Re-invigorating the University through Transdisciplinary Engagement
}

\author{
Gale Moore
}

gale.moore@utoronto.ca, The Knowledge Media Design Institute, University of Toronto, Canada

\begin{abstract}
The view that ICTs-and-Society is a transdiscipline offers great potential as a way forward. As the community moves toward a shared understanding of what constitutes transdisciplinary engagement a series of new questions are raised. This paper reflects on one of them - the question of how transdisciplinarity can be accomplished in the university. The argument advanced is that by re-framing the challenges of accommodating transdisciplinarity as an opportunity for institutional innovation there is potential to increase the support for research on ICTs-and-Society in the university, and to provide university administrators with a way to demonstrate leadership by adopting a broader innovation agenda that could re-invigorate the university and strengthen its relationship with the broader community in which it is situated.
\end{abstract}

Keywords: Disciplines, ICTs and Society, Innovation, Institutional innovation, Internet, Interdisciplinarity, Transdisciplinarity, Universities

Over the last two decades groups of scholars have come together in universities to conduct research that takes seriously the ideas raised by the notion of the Information Society ${ }^{1}$. The specific research foci, agendas and practices vary, but each is, in some way, concerned with understanding how people interact with each other, their artifacts and their environment; the design, development, use, and evaluation of information and communication technologies (ICTs), and the implications of these developments in the broader social and cultural context. While socio-technical approaches have been around since the late 1940s, access to the internet and the awareness of the penetration of ICTs into everyday life has captured the attention of a new generation of scholars. There have been illuminating debates as well as theoretical and methodological advances in the area broadly defined here as ICTs-and-Society. Since research in this field requires a broad base of collaboration across existing disciplines, it is not surprising that one of the early debates was around the form of interdisciplinarity appropriate to this area of research. Should the emerging field be understood as a proto-discipline in which the long-term goal is to attain disciplinary status? And if so, what should it be called? Or, alternately, is the move to disciplinise not in the best interest of the project in the long term? These debates have generated a rich literature, for example, a special issue of The Information Society was devoted to this question in 2005 (Baym), and this special issue of tripleC, recognises the developments since that time and asks whether ICTs-and-Society is a new transdiscipline?

The view of the field as a transdiscipline offers great potential as a way forward. This paper reflects on the challenges, both structural and intellectual, of doing transdisciplinary research in the university, and asks how might transdisciplinarity be accomplished in this context? The argument advanced is that by re-framing the challenges of accommodating transdisciplinarity as well as other forms of interdisciplinarity as an opportunity for institutional innovation there is potential to increase support for research on ICTs-and-Society in the university, and to offer university administrators a way to demonstrate leadership by adopting a broader innovation agenda that could re-invigorate the university and strengthen its relationship with the wider community of which it is a part.

\footnotetext{
${ }^{1}$ As the motive forces of the advanced economies shifts from production of goods and the management of capital and labor to an emphasis on information and knowledge as the key resource, the economic, cultural and social landscape is being transformed. Central to this shift is a cluster of innovations in information and communication technologies (ICTs).
} 


\section{Interdisciplinarity}

Interdisciplinarity, the term most often used to describe activities in which individuals from two or more disciplines are engaged, has a long history ${ }^{2}$ (UNESCO,1982; Klein, 1990, 1996, 2000). Interdisciplinarity became re-invigorated in the 1960s in response to the increased specialisation evident in the disciplines combined with a growing awareness of the complex and interconnected nature of many contemporary problems. The potential and value of disciplinary crossings have been recognised by the U.S. National Academies of Science and the U.S. Council of Graduate Schools. In a recent report the Council noted: "knowledge creation and innovation frequently occur at the interface of disciplines" (2007, p. 18). Facilitating Interdisciplinary Research, the 2005 report of the U.S. Committee on Science, Engineering, and Public Policy suggests that:

interdisciplinary thinking is rapidly becoming an integral feature of research as a result of four powerful "drivers": the inherent complexity of nature and society, the desire to explore problems and questions that are not confined to a single discipline, the need to solve societal problems, and the power of new technologies (Facilitating Interdisciplinary Research, 2005, p. 40).

The push for interdisciplinarity initiatives in the university may be "bottom-up"; driven by scholars whose pursuits lead them to new areas of research. The history of the emergent field of ICTs-andSociety is a good example. There is also a history of top down initiatives, and in the U.S. this had been a cause for concern. Jacobs and Frickel (2009) in a recent critical assessment of interdisciplinarity remark on the "widespread efforts to promote interdisciplinarity in U.S. universities" (p. 43) and the increased interest on the part of U.S. public and private funders (p. 45) in supporting such initiatives ${ }^{3}$. The concern is that these top down initiatives are motivated by recent American efforts "to configure the research university as an engine of economic and social change" (Brint, 2005, p. 23).

By enquiring into "the underlying assumptions about the nature of disciplines, research communities and universities and knowledge" (p. 48) on which the promotion of interdisciplinarity is based in the U.S., Jacobs and Frickel provide an important perspective. However, the authors fail to address what they characterise as the terminological ambiguity in the literature on interdisciplinarity:

Some scholars draw clear distinctions between research that is cross-disciplinary or multidisciplinary... or transdisciplinary... Others are more comfortable with looser distinctions. We count ourselves among the latter group and in this article use interdisciplinary and interdisciplinarity as general terms (Frickel, 2009, p. 45).

While this may be satisfactory for their argument, this position masks other forms of disciplinary crossings, and it is precisely through distinguishing among these different forms of interdisciplinary practice that we uncover the potential for creativity and innovation such disciplinary border crossings may afford. As well, differentiating among these forms provides a place from which to ask questions about the ways in which each forms adds value to scholarship and to the university.

The use of the term interdisciplinary as a general descriptor of disciplinary crossings is widely accepted. However, it is misleading as few projects achieve or even aspire to this form of disciplinary crossing. As Barthes notes in Jeunes chercheurs:

To do something interdisciplinary it's not enough to choose a subject (a theme) and gather round it two or three sciences. Interdisciplinary consists in creating a new object that belongs to no one (James, 1986, p.598).

\footnotetext{
${ }^{2}$ While some trace the origins of interdisciplinary back to Plato, the term was not coined until the 20th C (Klein, 1990, p.19) and this is the history relevant to this discussion.

${ }^{3}$ This includes, for example, the National Science Foundation, the National Institutes of Health, and the Mellon Foundation. This view of interdisciplinarity as an engine of economic growth may be most common in the U.S. where 'interdisciplinary creativity' according to Brint is seen as a strategy that may be most appealing to those institutions that "lack the resources to compete for disciplinary excellence" (2005, p.23).
} 
If the project of ICTs-and-Society is the creation of a new discipline there is much to be learned from the study of interdisciplinarity. If, however, the goal is to explore complex or systemic issues from multiple perspectives rather than to privilege any one way of knowing, multidisciplinary or transdisciplinary practices are more relevant. Facilitating Interdisciplinary Research describes multidisciplinary research as:

research that involves more than a single discipline in which each discipline makes a separate contribution. Investigators may share facilities and research approaches while working separately on distinct aspects of a problem. For example, an archeological program might require the participation of a geologist in a role that is primarily supportive. Multidisciplinary research often refers to efforts that are additive but not necessarily integrative (Facilitating Interdisciplinary Research, 2005, p. 27, 29).

The goal in multidisciplinary research is to explore issues from multiple perspectives where each discipline is relatively autonomous and approaches the problem according to their disciplinary norms.

A third type of crossing - transdisciplinarity - is the most radical form of practice. Transdisciplinary collaboration transcends traditional disciplinary boundaries and even transforms disciplinary identities to some degree. Here, "the point is not just application of given methodologies but also implication-a result of imagining entirely new possibilities for what disciplines can do" (Beyond Productivity, 2003, p. 99). In transdisciplinary research the primary focus is not on the discipline per se but on the generative and integrative potential of the interaction of individuals from different disciplines working together in the context of application. Figure 1 below shows this diagrammatically.

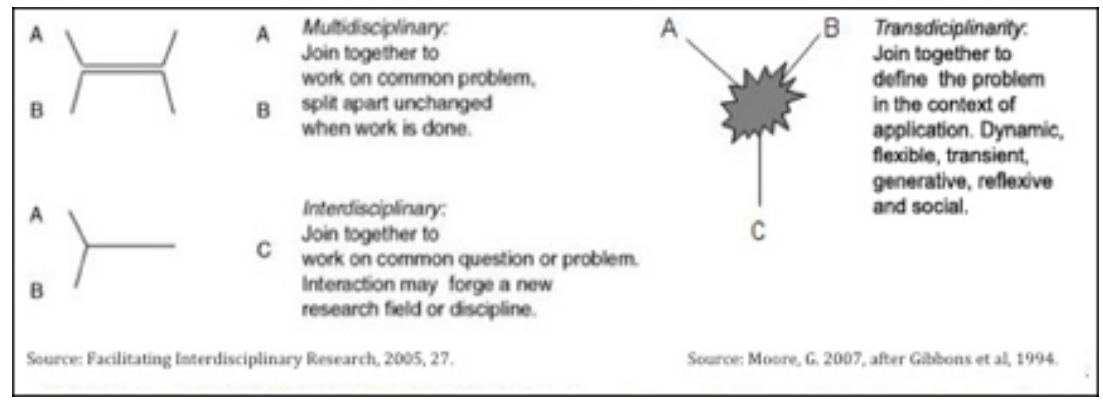

Figure 1: Multi-, inter- and transdisciplinary (Moore, 2009, p. 4)

While there is a degree of consensus on the meaning of transdisciplinary, there is not a single succinct definition that adequately describes this form. Hunsinger suggests that: "transdisciplinary research attempts to approach the object of study beyond and across disciplinary and interdisciplinary perspectives" (2005, p. 277).

Fuchs (2008) provides an overview of a number of attempts to characterise transdisciplinarity, and Hofkirchner et al. set out a detailed argument and rationale for their preference for the use of transdisciplinarity to describe ICTs-and-Society. They affirm that transdisciplinarity is an integrative concept and that the goal of transdisciplinarity is not to dissolve disciplinary competences (2007, p. 12). In a recent paper for the $2010 \mathrm{CHI}$ Conference Moore \& Lottridge (2010) express a similar view proposing the concept of disciplined transdisciplinarity to make this explicit. This framing recognises both the value of disciplinary depth as well as the need for new practices that foster and help negotiate what are, in essence, cultural and/or epistemological differences of those coming from different communities. It acknowledges the value of disciplinary traditions in conducting research while at the same time recognises the significance and legitimacy of knowledge claims that go beyond disciplinary norms. Most importantly, transdisciplinarity keeps the future open, and does not risk falling into the trap of disciplinary rigidity and institutionalisation, precisely what a project of interdisciplinarity risks if it succeeds. 
Transdisciplinarity also has a social function and accommodates what Frodeman, Mitcham and Sacks have called deep interdisciplinary - an engagement with the non-disciplinary public $(2000 / 2001$, p. 4). This adds a further challenge for the university as a wider public is potentially engaged in the creation of knowledge, but as Hunsinger reminds us: "Transdisciplinary knowledge, because it has recontextualized for the broader audience of multiple disciplines, is more accessible and interpretable" (2005, p. 278).

From this perspective, transdisciplinarity provides an opportunity for the university to demonstrate leadership in public access; a call increasingly being heard and funded. The public access funds of the Canadian Social Sciences and Humanities Research Council (SSHRC) are one example.

Transdisciplinarity - unlike interdisciplinarity - suggests a more radical and transformative engagement. Transdisciplinarity doubly disrupts the traditional academy. It not only disrupts traditional academic systems of accountability, evaluation and reward, it also disrupts the norms and values about what constitutes legitimate knowledge, and deeply held beliefs about what we know and how we know what we know.

\section{The University as a Site of Knowledge Production and the Role of Disciplines}

Universities, as institutions of higher learning and research, are a traditional site of scientific, social and cultural knowledge production and the primary employer of scholars and researchers in the humanities, social, physical and natural sciences. Disciplines ${ }^{4}$ are the way in which scholarship has traditionally been organised in the academy and within each discipline there are accepted norms and values around the production of knowledge. Squires correctly cautions that disciplines are neither timeless nor indivisible and that what we experience as disciplinary today is to some degree local and historically specific (1975, p. 40). As well, the social characteristics of knowledge production vary across the disciplines. However, in each case there is shared understanding and accepted norms and values about what constitutes a legitimate knowledge claim, and how claims should be supported, substantiated and validated.

Jacobs and Frickel point to Abbot as offering "the strongest recent statement regarding the durability of disciplinary social structures in the face of interdisciplinary pressures" $(2009$, p. 54). Abbott maintains that:

the basic disciplinary structure of the academy has changed little since the turn of the last century and that virtually all universities and colleges have lists of departments mirroring the original set of natural science, social sciences and humanities disciplines. Abbot traces this resilience to a dual institutionalization whereby disciplines structure the national academic labor markets as well as hiring practices at individual universities, which cannot move away from disciplinary organisation of departments without undermining their graduate students' opportunities to find employment at other universities (Jacobs \& Frickel 2009, p. 54).

Disciplines endure, "for intellectual as well as organisational reasons" (p.55). This point is more controversial and Turner notes that disciplinarity is conditioned by academic researchers dependence on students. Outside the university where disciplinarity is weak, "interdisciplinary and nondisciplinary forms flourish" (2000) $)^{5}$. Yet it continues to be a challenge for many scholars inside the academy to gain recognition for research that crosses current departmental boundaries. As Beth Casey notes:

\footnotetext{
4 "A branch of learning or a field of study characterized by a body of intersubjectively acceptable knowledge, pertaining to a well-defined realm of entities, systematically established on the basis of generally accepted principles with the help of methodical rules or procedures" (Kockelmans, 1979, p.127).

${ }^{5}$ We have observed this, for example, in the field of interaction design where teams are often interdisciplinary. While the potential of this diversity to inform research on ID is recognised, and multidisciplinary groups exist in places such as Microsoft Research and IDEO, research outcomes from such groups may not be considered a contribution that 'counts' within a traditional university department such as computer science (Moore \& Lottridge, 2010).
} 
Many universities and colleges today have a bureaucratic culture that assumes consensus and discounts controversy because it threatens organisational stability. Interdisciplinary leadership taps motivational bases and creates a climate in which risks can be taken and uncertainty and ambiguity are considered to be essential to the work that takes place (Casey, 1994, p. 66).

By extension when interdisciplinarity in all its forms is not well accommodated, the university as an institution loses an important opportunity to explore, experiment and potentially to innovate.

\section{Innovation}

Innovation is the creation of new social or economic value. Today, it is not uncommon to hear that innovation is the key to economic growth and sustainability or that world-class scientific research and technology development are essential drivers toward future prosperity. Universities increasingly embrace innovation, yet they largely do so in the limited way associated with a desire to translate primarily scientific and technological advances into financial returns. Less attention is paid to other types of innovation, and the value that results from creating, finding and/or combining knowledge into new or existing processes and services. The almost exclusive focus on the inventioncommercialization path to innovation ignores the possibilities inherent in what we call institutional innovation; an opportunity for the university to re-invent itself. By highlighting the incompatibility between existing institutional structures and the needs of scholars to create space for new and emerging ideas, interdisciplinary activities point to the areas in which innovation is needed.

Examples and models exist; several of which will be discussed in the next section, but much more could be done. Faculty and students engaged in research on ICTs-and-Society with an agenda increasingly defined as transdisciplinary are well-positioned to help the universities innovate. The expertise, as well as the subject, is increasingly not only relevant, but strategic to the future of the university. Re-framing what is required to accommodate new forms of knowledge production as a need for institutional innovation could potentially give scholars and university administrators a way to talk about re-inventing processes. Such a re-framing might also direct the attention of senior administrators to the consequences of the current institutional processes and structures and encourage support for experimentation. This could create a space within the university for new opportunities to emerge - opportunities that are missed when traditional structures, culture and values are too tightly entwined.

\section{Institutional Innovation}

Issues of institutionalisation and the legitimation of knowledge claims for transdisciplinarity have received little attention in the literature on interdisciplinarity. Yet, clarity on these points is important for the future development of projects and programs given the role of disciplines and departments in the creation and production of scholarly careers. The university also has a responsibility for educating future scholars and practitioners. Innovations in pedagogy and learning could go a long way toward developing more broadly educated and well-rounded individuals without the loss of disciplinary expertise or isolating them from the traditional academic labour markets.

We use Abbot's notion of 'dual institutionalization' to structure the next section on institutional structures and processes and to focus on the intellectual issues raised by interdisciplinary practices, in particular transdisciplinarity. These are areas critically in need of more research as well as the sharing of innovative strategies and practices. The goal is to enable leading edge research in emerging fields to find an intellectual home in our universities, in particularly in the elite institutions, at least in North America, where discipline and department are often closely aligned. Creative ways of working that are minimally disruptive to existing processes and practices are required if we are to advance this agenda quickly and to engage junior colleagues and graduate students. 


\subsection{Structure and Process}

Despite the challenges facing faculty whose research interests draw them into a form of interdisciplinary engagement, such activities continue to emerge. These may arise internally, or in response to external stimuli from government, or industry, for example. In this paper we are concerned with those communities in which scholars are drawn together because of shared intellectual interests in a particular set of questions.

One response by scholars has been to form a research centre or institute. Jacobs and Frickel estimate that in 2007 there were nearly 10,000 research centres in colleges and universities in the United States with nearly 100 per school at the 25 leading research universities $(2009$, p. 53); they observe that

strong disciplines combined with the flexibility to create diverse research centers as needed may be an attractive organizational solution to the challenges of organizing rapidly growing bodies of research and knowledge... (Jacobs \& Frickel, 2009, p.54).

We concur. The question of how to insert such centres or institutes into existing structures is an important one. While funding is always necessary, it is often not sufficient to assure either shortterm viability or long-term sustainability. For example, members of these communities may not have the experience, the time, or the visibility within the larger university to compete with established departments and faculties with the result that the centre may become isolated institutionally. This may be especially true in a field such ICTs-and-Society where, until recently, the significance of the research has not been always been well understood in the broader community.

In the spring of 2002 the author undertook a series of case studies on the experiences of five interdisciplinary scholarly communities in universities in Europe and the United Kingdom (Moore, 2004). The results provided one of the first systematic explorations of a number of interdisciplinary groups in universities that had emerged to take up, in various ways, the challenges raised by the notion of a Knowledge Society, and whose agendas were very similar to what is here called ICTsand-Society. The study was dually motivated. The first motive was pragmatic and the objective was to see if there were strategies or best practices that others had developed that could be deployed by the University of Toronto's Knowledge Media Design Institute (KMDI) ${ }^{6}$ with which the author was associated. The second motive was an interest in understanding more about the nature of the research questions that had initially brought each group together; what had led them to create a formal structure; how they determined the organisation form this has taken; and how they were situated in relation to the larger university structures, that is to say how the institute or center was institutionalised. We were curious to see if we could identify specific advantages or disadvantages inherent in the various organisational forms deployed that were independent of the local context or local opportunities.

The European setting was of special interest for a number of reasons. First, KMDI had emerged in part, out of the Ontario Telepresence Project, a project that had close relationships with a number of labs in both the United States and Europe active in the design, creation and use of audio/video mediated environments or 'media spaces' (Moore, 1997). Second, when KMDI was founded in 1995, we had adopted a human-centered design perspective in order to differentiate this new institute from other North American academic programs where the emphasis at the time was more techno-centric. Our goal was to bring a more nuanced understanding of people and their interactions with each other, with their tools and their environment into the design of ICTs, and to situate this within specific social/cultural contexts. The European philosophy of humancentredness, mapped well to Canadian sensibilities and longstanding social policy concerned with the public good. Third, we were aware that the European Union RTD (Research and Technology Development) had identified socio-economic research as a focus of activities to be carried out

\footnotetext{
${ }^{6}$ The history of the development of KMDI, the first scholarly community in this field in Canada, and the University of Toronto's first virtual institute, are in Moore \& Baecker, 2006.
} 
since the Fourth Framework Programme $(1994-1998)^{7}$. From a North American perspective this was a progressive research agenda with funding opportunities for what was emerging as a new area of interdisciplinary engagement.

The results from the five cases were encouraging in that each of the communities had found ways to accomplish their objectives within the institutions in which they were embedded. Yet, at the same time the ways in which each was institutionalised varied widely, and depended in most cases on local opportunities, initiatives, or a senior administrative champion. A worthwhile project going forward would be a more extensive study of the institutionalisation of the university groups engaged in ICTs-and-Society today, almost a decade after this project was completed, and to reflect deeply on the strategies that have worked and why. The development of a taxonomy of models, would not only be instructive for other groups facing these challenges, but collectively might stimulate the thinking required to create more innovative solutions.

There is also a need to define what constitutes success. The appropriate benchmarks and metrics for evaluation of an interdisciplinary institute, and the assessment of scholarly work in this context are likely to be significantly different from those used by traditional disciplinary units. While the strengths of individual members in any group is important, a set of measures that merely repeats and aggregates the academic quality indicators used in the disciplines would not capture or demonstrate the value of a network of people and resources that are generated through collaboration. As long as evaluation and reward systems for faculty in an institute are controlled externally and dependent on the goodwill of faculty deans and department chairs, this is not unexpected. But it may not be sustainable. This too is a worthwhile a project that could potentially be undertaken with other scholarly communities such as those reviewed here.

Transdisciplinary approaches present the greatest challenge to the dominant mode of knowledge production as transdisciplinarity disrupts traditional academic systems of accountability, evaluation and reward. In the university a new way to assess or to evaluate these practices is required if the area is to be accepted as legitimate, and to enable wider participation in this type of research by faculty and graduate students. This is a complex challenge both for individuals and for the institution. On the one hand, those engaged in transdisciplinary practices need to shoulder some of the responsibility for developing an alternative evaluation scheme, and it is in their interest to do so. They have the expertise to enumerate what is most valuable in these new forms and to describe what constitutes success. However, this type of accounting activity is seldom of interest to researchers and scholars. On the other hand, unless there are senior administrators who recognise the innovative potential of various forms of interdisciplinarity there is little incentive for the university to undertake the development of schemes to accommodate and evaluate the outputs of these forms of research practice.

The development of metrics was an activity KMDI identified in its 2003 strategic plan. Our objective was to define measures that tell us something about the strength of interdisciplinary collaborations and the role that KMDI plays in nurturing them; the institute's ability to provide a coherent intellectual framework for inter-, multi- and transdisciplinary work; and our ability to create and lead a broader intellectual community. Examples include the extent to which KMDI members sit on doctoral committees in departments or faculties other than their own; the number of grants and refereed publications per year co-authored by KMDI members from two or more different academic units, and cross-disciplinary citations of the work of KMDI members - i.e., citations in papers that are published in a different discipline from the KMDI work they cite. However, much work remains to be done to establish the validity and utility of such measures, and to create more innovative ways to assess inter-, multi- and transdisciplinary activities. This is another project that the ICTsand-Society scholars might undertake collectively.

Research is also needed on new models of accommodation - models that are reasonably low risk for the institution but that provide sufficient stability for the interdisciplinary teams for an adequate length of time. If there is no risk to the institution, it is unlikely there will be innovation. If there

\footnotetext{
${ }^{7}$ This direction was extended in the Fifth Framework (1998-2002) with the establishment of the Information Society Technologies (IST) and continued to be a thematic priority in the Sixth Framework Programme (2003-2006).
} 
is no stability for interdisciplinarity, these communities are less likely to form or to be sustainable. In addition, the institution must innovate in terms of the professional and administrative structures structures that assist and encourage faculty as well as departments and faculties to participate. It will not be easy, and those who advocate interdisciplinarity need to pay attention to the ways in which interdisciplinarity challenges the basic institutional structure and processes of the university. Innovation is a disruptive process.

There is also need for structures to support graduate education in fields such as ICTs-andSociety. For transdisciplinary research centres or institutes that have graduate programs, the question of how students will fit into the academic labour markets on graduation is a question that must be answered. KMDI was fortunate in this respect as the Collaborative Program model administered by the University of Toronto's School of Graduate Studies provided an institutional process that supported our ambitions to offer graduate education in which students from more than one discipline could participate. Non-degree granting collaborative programs emerge from cooperation between two or more graduate departments, centres, and institutes and provide students with a broader base from which to explore a novel interdisciplinary area or developments in another discipline to complement their degree studies. ${ }^{8}$ In 2002, KMDI launched the Collaborative Masters and Doctoral Program in Knowledge Media Design, and today there are ten academic units participating. The model has been excellent in many ways in that it provides an administratively lightweight way for the institute to build a graduate program as the student's relationship with the university is coordinated through their home department while at the same time giving students access to faculty from across a large number of disciplines. There is a reciprocal benefit for faculty engaged in projects requiring broad participation, and at the same time, assures that students will graduate with a degree from a recognised discipline. In general, students enrolled in the program identify strongly with the institute and with the research in this area. The disadvantage at the present time is that there is not a standard approach to cost recovery from the students' home departments and the cost is borne by the institute out of the small base budget received from the university.

In the next section we consider the intellectual issues transdisciplinarity raises. Here too, innovative new models are emerging, in particularly in the area of pedagogy. And once again, more needs to be done, and this too is a topic that could be added to a collective research agenda for ICTsand-Society.

\subsection{The Intellectual Challenges Posed by Transdisciplinary Engagement in the University}

A critical first step in responding to the challenges interdisciplinary crossings pose to traditional forms of knowledge production is to differentiate among the forms of interdisciplinarity each of which has merit. The difference among the forms is instructive in terms of the intellectual challenges each poses for the university. Some interdisciplinary programs have successfully institutionalised as a new discipline - e.g., cognitive science or women's studies. In these cases the new discipline largely reproduces the well-understood apparatus of knowledge production. Multidisciplinary approaches are also minimally disruptive and do not require significant institutional reform to accommodate them as the participants continue to be part of their disciplinary culture. It is the transdisciplinary approaches that are the least familiar that present the greatest challenge to the dominant mode of knowledge production, not because there are multiple disciplines involved, but because of the generative nature of the process, and because the nature of the knowledge produced does not fit neatly into individual disciplinary categories or cultures.

Transdisciplinarity disrupts not only traditional academic systems of accountability, evaluation and reward, but challenges the norms and values around the production of knowledge in fundamental ways. By accepting that there are irreconcilable notions of truth, transdisciplinarity has the potential to create deeper understandings, to enhance creativity and to intellectually enrich those participating. The development of scholars and practitioners who can engage in this way should be central to the work of the academy. Why is it so difficult?

\footnotetext{
${ }^{8}$ Source: http://www.gradschool.utoronto.ca/programs/collaborative.htm.
} 
As a shared understanding of transdisciplinarity and what constitutes it is still evolving, we return to the formulation by Gibbons et al. (1994) that sets out four distinct features of transdisciplinarity, as these make clear the challenges this type of knowledge production raise.

First, it develops a distinct but evolving framework to guide problem solving efforts. ... Although elements of existing knowledge must have entered into it, genuine creativity is involved and the theoretical consensus, once attained cannot easily be reduced. ...Second, because the solution comprises both empirical and theoretical components it is undeniably a contribution to knowledge, though not necessarily disciplinary knowledge. ... Third, ...the diffusion of the results is initially accomplished in the process of their production. Subsequent diffusion occurs primarily as the original practitioners move to new problem contexts rather than through reporting results in professional journals or at conferences. Fourth, transdisciplinarity is dynamic. A particular solution can become the cognitive site from which further advances can be made. ... New knowledge produced in this way may not fit into any one of the disciplines that contributed to the solution. Nor may it be easily referred to particular disciplinary institutions or recorded as disciplinary contributions (Gibbons et al., 1994, p. 5).

This is virtually orthogonal to traditional disciplinary institutional values. Yet, transdisciplinarity is especially valuable when the issues are complex or systemic - the kind of issues of interest to scholars working in ICTs-and-Society.

We can see why this is so difficult in the traditional university. Academics engaging in research in ICTs-and-Society or other transdisciplinary fields may produce work where well-understood disciplinary standards do not apply. Promotion and tenure committees as well as granting agencies rely on "well known" or "familiar" disciplinary standards in the epistemic community to recognize the value of the research. Scholars, engaging in interdisciplinary projects may produce work that does not conform to the traditional norms of the discipline that is evaluating them. For example, the results may be published in a journal outside the discipline, or an altogether different means of dissemination altogether may have been found to be more suitable. How then can their contributions be evaluated? What kind of innovation in the tenure and promotion process might be required to recognise a more diverse range of contributions? Klein, Jacobs and Frickel note that:

the criteria for judgment constitute the least understood aspect of interdisciplinarity, in part because the issue has been the least studied and in part because the multiplicity of tasks seems to militate against a single standard (Klein, Jacobs \& Frickel, 2009, p. 52).

If the field is to attract young scholars, what modifications to the processes of tenure and promotion might be required to recognise these contributions?

There are, however, reasons for optimism. Faculty and students have been engaged in what is called here ICTs-and-Society for fifteen to twenty years. Despite the institutional challenges faced, a succession of research centres, labs and institutes have formed in this area, and a growing body of knowledge has been created and disseminated formally as part of the corpus of several disciplines, through the creation of new interdisciplinary publications, through new forms of digital distribution, and informally within the community. Second, the university as a traditional site of knowledge production has invested in infrastructure, in terms of its libraries and computer networks, and more recently has been experimenting with a variety of projects around open access and open innovation. The turn to the digital is enabling scholars to participate in novel ways in new configurations and in rethinking the nature of scholarly communication itself. Third, federal funding programs now exist in Canada that require participation in the community, for example, the CommunityUniversity Research Alliances (CURA) research grants ${ }^{9}$ and public outreach funds mentioned earlier that support knowledge transfer, or knowledge mobilisation activities in the community.

\footnotetext{
${ }^{9}$ The purpose of the program is to support the creation of alliances between community organizations and postsecondary institutions which, through a process of ongoing collaboration and mutual learning, will foster innovative research, training and the creation of new knowledge in areas of importance for the social, cultural or economic development of Canadian communities.
} 
This is not to suggest that this achieves or even approximates the kind of change that is required if significant transdisciplinary engagement is to take place in the university. However, it does suggest that the timing may be right to launch more ambitious and novel explorations and experiments. ICTs-and-Society in its aspiration to transdisciplinarity and its broad substantive concerns is well positioned to start a dialogue on how to systematically recognize the challenges and opportunities raised by transdisciplinary research in the university generally and in terms of ICTs-and-Society specifically. Taking an innovation perspective, the question is not whether the university can accommodate this engagement of disciplines and intellectual traditions in ways that make it possible for a field such as ICTs-and-Society to evolve in the university, but how it can be accomplished.

There is value both in diversity and in discipline. Training future scholars and practitioners who wish to engage in transdisciplinarity is an essential part of the way forward. Gerhard Fischer argues that there is a need to develop transdisciplinarity competencies that "refer to knowledge and skills required to identify, frame and address important scientific and practical problems that cut across disciplinary boundaries" $(2003$, p. 3). With Fischer we see innovations in pedagogy as critical in preparing the next generation of graduate students for the challenges they will face as researchers and as practitioners. Innovations on this front may be easier to achieve. The stakes are high. If transdisciplinarity cannot be accomplished within the academy, or junior scholars cannot participate, then much will be lost - both intellectually and to the universities who are looked to for new thinking and innovative ideas.

\section{Conclusion}

Universities are traditional institutions with long established structures such as departments, faculties and schools organised around disciplines that manage and control the distribution of rewards and the orderly production of a scholarly career. Knowledge production takes place within wellunderstood parameters, and while there are differences between fields, the legitimation of knowledge claims within any field is held to be the responsibility of the disciplinary or epistemic community of which it is a part. In terms of pedagogy, the lecture and seminar are traditional forms used across the institution in the production of high quality personnel. These structures and processes have served well for decades, if not centuries, and continue to serve well in parts of the academy. However, the increased complexity, uncertainty, and connectedness of contemporary societies, new capabilities with the turn to the digital, and the centrality of knowledge to future well-being and sustainability requires new models. A transdisciplinary approach appears to offer a way forward for ICTs-and-Society. In the context of the university can this move be articulated in ways that the institution is able to adopt?

Innovation and the creativity that drives it are understood to be strategic in bringing the university into the 21 st century. By framing the institutional reform required to accomplish transdisciplinarity as institutional innovation we call for a re-invention of the university. This re-invention has the potential to create new social value and to highlight the creative, generative and integrative nature of transdisciplinary practice. It is precisely in working through the tensions of working across disciplines, across boundaries of practice and theory, and working collaboratively through community engagement, where the potential for the re-invigoration of the university lies.

ICT-and-Society scholars are part of consciously inventing the way to a transdisciplinary future. The relevance of the 21st century university may just depend on their ability to find creative solutions to this challenge. 



\section{References}

Baym, N. K. (2005). Introduction: Internet Research as It Isn't, Could Be, and Should Be. The Information Society 21(4), 229-232.

Brint, S. (2005). Creating the future: 'new directions' in American research universities. Minerva 43(1), 23-50.

Casey, B. A. (1994). The Administration and Governance of Interdisciplinary Programs. In J.T. Klein \& W.G. Doty (Eds.), Interdisciplinary Studies Today (pp. 53-67). San Francisco: Jossey-Bass.

Facilitating Interdisciplinary Research (2005). Committee on Facilitating Interdisciplinary Research, Committee on Science, Engineering, and Public Policy, National Academy of Sciences, National Academy of Engineering, and Institute of Medicine. Washington, D.C.: National Academies Press.

Fallman, D. (2008.) The Interaction Design Research Triangle of Design Practice, Design Studies and Design Exploration. Design Issues 24(3), 4-18.

Fischer, G. \& Redmiles, D. (2008). Transdisciplinary Education and Collaboration. Contribution to the Human Computer Interaction Consortium ( $\mathrm{HClC}$ ) Workshop 2008; Education in $\mathrm{HCl}$; $\mathrm{HCl}$ in Education. Retrieved from http:///3d.cs.colorado.edu/ gerhard/papers/hcic2008.pdf

Frodeman, R., Mitcham, C. \& Sacks, A.B. (2000/2001). Questioning Interdisciplinarity. Science, Technology and Society Newsletter, 126 \& 127, 1-5.

Fuchs, C. (2008.) Introduction to the Special Issue on ICTs and Society: PhD Students' Transdisciplinary Research Projects. triplec 6(2), i -viii.

Gibbons, M., Limoges, C., Nowotny, H., Schwartzman, S., Scott, P. \& Trow, M. (1994). The New Production of Knowledge: The Dynamics of Science and Research in Contemporary Societies. London: Sage.

Hofkirchner, W., Fuchs, C. Raffl, C., Schafranek, M., Sandoval, M. \& Bichler, R. (2007). ICTs and Society: The Salzburg Approach. Towards a Theory For, About and by Means of the Information Society. ICT\&S Center Research Paper No. 3. Retrieved from http://icts.sbg.ac.at/media/pdf/pdf1490.pdf

Hunsinger, J. (2005). Toward a Transdisciplinary Internet Research. The Information Society 21(4), 277-279.

Jacobs, J. A. \& Frickel, S. (2009). Interdisciplinarity: A Critical Assessment. Annual Review of Sociology 35, 43-65.

James, C. (1986). Introduction: Partial Truths. In P.A. Erickson \& L.D. Murphy (Eds.), Readings for a History of Anthropological Theory (pp. 598-630). Lancashire: Broadview Press.

Klein, J.T. (2000). A Conceptual Vocabulary of Interdisciplinary Science. In Weingart, P. \& Stehr, N. (Eds.), Practising Interdisciplinarity (pp. 3- 24). Toronto: University of Toronto Press.

Klein, J.T. (1990). Interdisciplinarity: History, Theory and Practice. Detroit, MI: Wayne State University Press.

Klein, J.T. (1996.) Crossing Boundaries: Knowledge, Disciplinarities and Interdisciplinarities. Charlottesville: University Press of Virginia.

Kockelmans, J. J. (1979.) Why Interdisciplinarity? In J.J. Kockelmans (Ed.), Interdisciplinarity and Higher Education (pp. 123-160). University Park: The Pennsylvania State University Press.

Mitchell, W. J., Inouye, A. S. \& Blumenthal, M. S. (Eds.) (2003). Beyond Productivity: Information, Technology, Innovation, and Creativity. Washington, DC: National Academies Press.

Moore, G. (2003). Researching the Knowledge Society: Interdisciplinarity and Innovation in the University. Presented at the 4th International Conference on Technology, Policy and Innovation, Monterrey, Mexico, June 2003. (Published as KMDI Working Paper, KMDI-WP-2003-3).

Moore, G. (2009). Re(defining) Interdisciplinarity: Re(forming) Universities. In Interrogations: Creative Interdisciplinarity in Art \& Design Research (pp. 13-24). Loughborough: Interrogations Conference Committee, DeMontfort University Faculty of Art and Design \& Loughborough University School of Art and Design.

Moore, G. (1997). Sharing Faces, Places and Spaces: The Ontario Telepresence Project Field Studies. In Finn, K., Sellen, A.J. \& Wilbur, S. (Eds.), Video-Mediated Communication (pp. 301-321). Mahwah, N.J.: Lawrence Erlbaum Assoc.

Moore, G. \& Baecker, R.M.B. (2006). The Knowledge Media Design Institute: An Adventure in Interdisciplinarity. In: Eibl, M., Reiterer, H., Stephan, P., Thiessen, F. (Eds.), Knowledge Media Design: Theorie, Methodik, Praxis (pp. 409-420). 2d.ed. Munich: Oldenbourg Verlag.

Moore, G. \& Lottridge, D. (2010). Interaction Design in the University: Designing Disciplinary Interactions. CHI 2010, April 10-15, 2010, Atlanta, GA. [in press].

Nowotny, H., Scott, P. \& Gibbon, M. (2003). Introduction: 'Mode 2' revisited: The New Production of Knowledge. Minerva, 41(3), 179-194.

Turner, S. (2000). What are Disciplines? And How is Interdisciplinarity Difference? In: Weingart, P. \& Stehr,N. (Eds.), Practising Interdisciplinarity (pp.46-65). Toronto: University of Toronto Press.

UNESCO. European Centre for Higher Education (1983). Interdisciplinarity in Higher Education: A Study. Bucharest: European Centre for Higher Education. 


\section{About the Author}

Gale Moore

is a member of the graduate faculty, Dept. of Sociology, University of Toronto; Senior Fellow and former director of the University of Toronto's Knowledge Media Design Institute, and adjunct faculty in OCAD University's graduate program in Strategic Foresight \& Innovation. Her primary interests for the past 20 years have been the social impacts of ICTs in everyday life, and on bringing an understanding of peoples' experience and interaction with technology into the design of technical artifacts. She has a longstanding interest in institutional innovation and the ways various forms of interdisciplinarity enhance creativity and foster innovation. 